\title{
Understanding Cognitive Failures through Psychosocial Variables in Daily Life of Students
}

\author{
Amela Dzubur ${ }^{1}$, Maida Koso-Drljevic ${ }^{2}$, Delila Lisica ${ }^{3}$ \\ ${ }^{1,3}$ Department of Public Health, University of Sarajevo, Sarajevo, Bosnia and Herzegovina. \\ ${ }^{2}$ Department of Psychology, University of Sarajevo, Sarajevo, Bosnia and Herzegovina.
}

\section{ABSTRACT}

\section{BACKGROUND}

Cognitive failures impair the quality of life. Students are often exposed to stressful situations, struggle to make a balance in life, have time management issues and tend to procrastinate, feel too much pressure to succeed, and find it difficult to cope with study and exam anxiety. In this study, we investigated cognitive failures through psychosocial variables in daily life of students and relationship between anxiety and cognitive failures.

\section{METHODS}

A cross-sectional study was conducted among 175 students (78.29 \% female and $21.71 \%$ male). Medical students comprised $52.57 \%$ of the sample ( $n=92)$, while $47.43 \%$ were psychology students $(n=83)$. All students were in the first year of education at University of Sarajevo. The survey used the sociodemographic questionnaire, State-Trait Anxiety (Form Y), Cognitive Failures Questionnaire CFQ. Results were obtained by independent sample test and Pearson's correlation coefficient (r).

\section{RESULTS}

Using pharmacotherapy was common among students. Medical students ( $n=55)$ have used pharmacotherapy twice as frequently in comparison to $32.1 \%(n=26)$ of psychology students. Comparing results of students, there were statistically significant differences between consumption of pharmacotherapy, cigarettes, alcohol and anxiety in experience of cognitive failures. Out of 175 students, 130 (74.29\%) have high level of anxiety. Anxiety was statistically significantly correlated with the total of cognitive failures, but also with forgetfulness, distractibility, and false triggering subscales. The largest association was with total CFQ $(r=0.453, p<0.01)$.

\section{CONCLUSIONS}

Results of this study show that variables such as consuming alcohol, cigarettes, painkillers, and anxiety could cause cognitive failures. Student life in addition to the obligations and pressures created by academic engagement itself involves many changes and just thinking about it can cause anxiety symptoms. Accordingly, the undesirable outcomes that cognitive failures can cause maladaptive student habits and anxiety. It should be a treated as a critical public health issue.

\section{KEY WORDS}

Cognitive Failure, Anxiety, Nicotine, Alcohol, Analgesics
Corresponding Author: Mrs. Delila Lisica. Medical Faculty, Department of Public Health, University of Sarajevo, Čekaluša 90, 71000 Sarajevo, Bosnia and Herzegovina. E-mail: delila.lisica@gmail.com

DOI: $10.14260 /$ jemds/2020/743

How to Cite This Article:

Džubur A, Koso-Drljević M, Lisica D. Understanding cognitive failures through psychosocial variables in daily life of students. J Evolution Med Dent Sci 2020;9(45):3382-3386, DOI: 10.14260/jemds/2020/743

Submission 04-08-2020,

Peer Review 28-09-2020,

Acceptance 05-10-2020,

Published 09-11-2020.

Copyright (c) 2020 Amela Džubur et al. This is an open access article distributed under Creative Commons Attribution License [Attribution 4.0 International (CC BY 4.0)] 


\section{BACKGROUND}

Sometimes, we all make minor mistakes when performing certain tasks. However, if cognitive errors occur frequently, they can cause serious problems and interfere with successful performance of routine activities. Cognitive impairment refers to mistakes and inabilities in the performance of everyday tasks that a person is otherwise capable of doing. In general, these failures can be related to memory (such as inability to remember information), perception and motor functioning, 1,2 such as forget names or important appointments, don't notice the traffic signs or don't know if the door is locked.

Cognitive failures correlate with attentional control and frequency of errors through the day, correlate with ability to sustain, switch or inhibit attention. ${ }^{3}$ According to the extended Unsworth $^{4}$ study, intra-individual variability is not an individual unitary factor. The findings suggest that intraindividual variability in attentional control is a stable trait, but in addition to attentional control, it is also associated with a number of other important abilities that predict cognitive failures in real life. 4

Cognitive failures impair the quality of life since in some situations mistakes that are made can have serious and lifethreatening consequences. Distracting environments, time pressure or chaotic surroundings increases the possibility of making mistakes. ${ }^{5}$

According to the available literature, they include the effects of situational factors, transient psychological states, and neurological variables. ${ }^{6}$ Personality traits such as neuroticism, schizotypy and anxiety maintain difficulties in emotional regulation, which determine the sensitivity of cognitive capacities to external stressors. According to several research cognitive failure associated with stress, high anxiety ${ }^{6}$ 9 and academic outcome. ${ }^{3}$ Students are often exposed to stressful situations, struggle to make a balance in life, they have a problem with time management issues and procrastination, feel too much pressure to succeed, difficulty coping with study and exam anxiety. ${ }^{10}$

Difficulties in controlling impulses, exercising purposeful behaviour, and lack of appropriate emotion regulation strategies are the most important factors for substance abuse among students. ${ }^{11}$ Higher rates of cigarette smoking and alcohol consumption among university students are a significant public health concern. Cigarette smoking and alcohol consumption were in correlation with stress.11,12 According to the study by Heydari, ${ }^{11}$ the factors that had the highest association with nicotine were related to the perception of task volume, time limit, tests. ${ }^{11}$ Alcohol consumption in the student population places greater emphasis on drunkenness than in the elderly. ${ }^{13}$ The aim of this research was to examine the relationship between anxiety and cognitive failures, also which variables do impact on cognitive failures and make various difficulties in daily life of students.

\section{METHODS}

\section{Study Design, Participants and Procedure}

This cross-sectional study was conducted in 2019 and enrolled 175 students (78.29 \% female and $21.71 \%$ male). Medical students comprised $52.57 \%$ of the sample $(n=92)$, whilst $47.43 \%$ were psychology students $(\mathrm{n}=83)$. All students were in the first year of education and participation was on a voluntary basis. Examines were given instructions to read carefully the questions and to answer them honestly. Completing the questionnaires was after the lectures a week before the exams and took about 15 minutes. The study was approved by the Ethics Committee of the Medical Faculty, University of Sarajevo Bosnia and Herzegovina. Informed consent was obtained from all study participants prior to data collection.

\section{Measures}

The sociodemographic questionnaire, State-Trait Anxiety (Form Y), ${ }^{14}$ Cognitive Failures Questionnaire $\mathrm{CFQ}^{1}$ were used.

The sociodemographic questionnaire consists of basic information such as gender, dominant hand, whether the student has a chronic illness, has ever lost consciousness, whether he / she currently uses pharmacotherapy, cigarettes, alcohol, and how often.

State-Trait Anxiety Inventory STAI-Form Y was designed to assess levels of state anxiety through 20 items scored by a 4-point Likert-scale from 1 (not at all) to 4 (very much so). State anxiety can be defined as a transient momentary emotional status that results from situational stress. Good to excellent internal consistency (Cronbach's alpha $=89-.96) .{ }^{14}$ In the present sample the internal consistency reliability (Cronbach's alpha) of this measure was 0.918.

Cognitive Failures Questionnaire - This scale was used to assess how frequently participants commit errors in the completion of everyday tasks. The cognitive failures comprise 25 items derived from three areas of slips and errors: perception slips, memory slips, and slips in motor functioning. For each described cognitive failure, participants were asked to rate on a 5-point Likert-scale from 0 (never) to 4 (very often). Scores were compiled by adding total ratings, with scores range from 0 to 100 . A study by Rast et al.15 indicates that the CFQ items load on three different factors, forgetfulness, distractibility and false triggering. The CFQ has a good test-retest reliability, with stability coefficients at approximately internal consistency reliability (Cronbach's alpha $=80$ ) across 6 to 65 weeks, indicating a high degree of stability of individual differences. ${ }^{1}$ In the present sample the internal consistency reliability (Cronbach's alpha) of this measure was 0.882 .

\section{Statistical Analysis}

The collected data was analysed using descriptive and inferential statistics via the SPSS software version 21 (IBM Inc., Armonk, NY, USA) and by parametric procedures. For data processing Independent sample test and Pearson's correlation coefficient (r) were used. Means (percentages) and frequencies were reported for quantitative and qualitative variables, respectively. The significance level for all statistical tests was set at the $\mathrm{p}<0.05$.

\section{RESULTS}

Sociodemographic variables, anxiety and difference between participants in experience of cognitive failures are presented 
in Table 1. As the results show, there were no statistically significant difference between education program, gender and dominant hand in experience of cognitive failures. Comparing response from those who have high anxiety and low score of anxiety showed significant differences in experience of cognitive failures $(t=4.587 ; p<0.001)$. Significant differences in experience of cognitive failures were between students who were consuming pharmacotherapy $(\mathrm{t}=-2.028 ; \mathrm{p}<0.05)$, who were consuming cigarettes and non-smokers $(\mathrm{t}=-2.450$; $\mathrm{p}<$ $0.05)$, consuming and not consuming alcohol $(\mathrm{t}=-2.995 ; \mathrm{p}<$ 0.01).

\begin{tabular}{|c|c|c|c|c|c|c|}
\hline Variables & $\mathbf{N}$ & $\%$ & M & SD & t & p \\
\hline $\begin{array}{c}\text { Students } \\
\text { Medical Students } \\
\text { Psychology Students }\end{array}$ & $\begin{array}{l}92 \\
83\end{array}$ & $\begin{array}{l}52.57 \\
47.43\end{array}$ & $\begin{array}{l}40.23 \\
37.55\end{array}$ & $\begin{array}{l}13.63 \\
12.35\end{array}$ & 1.355 & 0.177 \\
\hline $\begin{array}{l}\text { Gender } \\
\text { Male } \\
\text { Female }\end{array}$ & $\begin{array}{c}38 \\
137\end{array}$ & $\begin{array}{l}21.71 \\
78.29\end{array}$ & $\begin{array}{l}37.74 \\
39.30\end{array}$ & $\begin{array}{l}13.06 \\
13.09\end{array}$ & -0.651 & 0.516 \\
\hline $\begin{array}{l}\text { Dominant Hand } \\
\text { Right } \\
\text { Left }\end{array}$ & $\begin{array}{c}156 \\
19\end{array}$ & $\begin{array}{l}89.14 \\
10.86\end{array}$ & $\begin{array}{l}38.37 \\
43.84\end{array}$ & $\begin{array}{l}12.78 \\
14.70\end{array}$ & -1.735 & 0.085 \\
\hline $\begin{array}{c}\text { Consuming of any } \\
\text { Pharmacotherapy } \\
\text { Yes } \\
\text { No }\end{array}$ & $\begin{array}{l}81 \\
94\end{array}$ & $\begin{array}{l}46.29 \\
53.71\end{array}$ & $\begin{array}{l}41.10 \\
37.12\end{array}$ & $\begin{array}{l}12.50 \\
13.33\end{array}$ & -2.028 & 0.044 \\
\hline $\begin{array}{c}\text { Consuming Cigarettes } \\
\text { Yes } \\
\text { No }\end{array}$ & $\begin{array}{c}33 \\
142\end{array}$ & $\begin{array}{l}18.86 \\
81.14\end{array}$ & $\begin{array}{l}43.91 \\
37.81\end{array}$ & $\begin{array}{l}12.03 \\
13.07\end{array}$ & -2.450 & 0.015 \\
\hline $\begin{array}{c}\text { Consuming Alcohol } \\
\text { Yes } \\
\text { No }\end{array}$ & $\begin{array}{c}57 \\
118\end{array}$ & $\begin{array}{l}32.57 \\
67.43\end{array}$ & $\begin{array}{l}43.12 \\
36.95\end{array}$ & $\begin{array}{l}12.91 \\
12.72\end{array}$ & -2.995 & 0.003 \\
\hline $\begin{array}{c}\text { Anxiety } \\
40 \text { and above } \\
\text { Belong } 40 \\
\end{array}$ & $\begin{array}{c}130 \\
45 \\
\end{array}$ & $\begin{array}{r}74.29 \\
25.71 \\
\end{array}$ & $\begin{array}{l}41.48 \\
31.67 \\
\end{array}$ & $\begin{array}{l}12.67 \\
11.46 \\
\end{array}$ & 4.587 & 0.000 \\
\hline & 11 & $\overline{\text { pend }}$ & t $\mathrm{Sam}_{\mathrm{l}}$ & $\begin{array}{l}\text { Test of } \\
\text { Idents }\end{array}$ & & \\
\hline
\end{tabular}

\begin{tabular}{|c|c|c|c|c|c|c|}
\hline \multirow[t]{2}{*}{ Variables } & \multicolumn{2}{|c|}{ Medical Students } & \multicolumn{2}{|c|}{$\begin{array}{l}\text { Psychological } \\
\text { Students }\end{array}$} & \multicolumn{2}{|c|}{ Total } \\
\hline & $\begin{array}{c}\text { Female } \\
\mathrm{n}(\%)\end{array}$ & $\begin{array}{l}\text { Male } \\
\text { N (\%) }\end{array}$ & $\begin{array}{c}\text { Female } \\
\text { N (\%) }\end{array}$ & $\begin{array}{l}\text { Male } \\
\text { N (\%) }\end{array}$ & $\begin{array}{c}\text { Female } \\
\text { N (\%) }\end{array}$ & $\begin{array}{c}\text { Male } \\
\text { N (\%) }\end{array}$ \\
\hline Analgesics & $\begin{array}{c}28(34.57 \\
\%)\end{array}$ & $5(6.17 \%)$ & $\begin{array}{c}13(16.05 \\
\%)\end{array}$ & $1(1.23 \%)$ & $\begin{array}{c}41(50.62 \\
\%)\end{array}$ & $6(7.41 \%)$ \\
\hline Antibiotics & $6(7.41 \%)$ & $1(1.23 \%)$ & $2(2.47 \%)$ & 0 & $8(9.88 \%)$ & $1(1.23 \%)$ \\
\hline $\begin{array}{l}\text { Antidepressi } \\
\text { ve }\end{array}$ & $3(3.70 \%)$ & $1(1.23 \%)$ & 0 & 0 & $3(3.70 \%)$ & $1(1.23 \%)$ \\
\hline $\begin{array}{l}\text { Analgesics \& } \\
\text { Antidepressi } \\
\text { ve }\end{array}$ & $3(3.7$ & 0 & $1(1.23 \%)$ & 0 & $4(4.93 \%)$ & 0 \\
\hline $\begin{array}{l}\text { Other } \\
\text { (Allergies, } \\
\text { Hormonal } \\
\text { Therapy) }\end{array}$ & $6(7.41 \%)$ & $2(2.47 \%)$ & $8(9.88 \%)$ & $1(1.23 \%)$ & $\begin{array}{c}14(17.28 \\
\%)\end{array}$ & $3(3.70 \%)$ \\
\hline Total & $\begin{array}{c}46(56.79 \\
\%)\end{array}$ & $\begin{array}{c}9(11.11 \\
\%)\end{array}$ & $\begin{array}{c}24(29.63 \\
\%)\end{array}$ & $2(2.47 \%)$ & $\begin{array}{c}70(86.42 \\
\%)\end{array}$ & $\begin{array}{c}11(13.58 \\
\%)\end{array}$ \\
\hline & Tal & Frequ & $y$ of $P I$ & & apy & \\
\hline
\end{tabular}

According to the results obtained in Table 2, $58.03 \%$ of students report to have used analgesics, $4.93 \%$ sedatives and $4.93 \%$ combination of sedatives and analgesics. The results show that $86.42 \%$ of the female students consumed pharmacotherapy compared to $13.58 \%$ of the male students. As showed in table $67.9 \%$ of medical students consumed pharmacotherapy and $32.1 \%$ of psychological students.

\begin{tabular}{|c|c|c|c|c|}
\hline & $\begin{array}{cc}\text { State } & \text { Cognitive } \\
\text { Anxiety Failures Total }\end{array}$ & $\begin{array}{l}\text { Forget- } \\
\text { fulness }\end{array}$ & $\begin{array}{l}\text { Distracti- } \\
\text { bility }\end{array}$ & $\begin{array}{c}\text { False } \\
\text { Triggering }\end{array}$ \\
\hline State Anxiety & $.453 \dagger$ & $.355 \dagger$ & $.427 \dagger$ & $.347 \dagger$ \\
\hline $\begin{array}{c}\text { Cognitive } \\
\text { Failures Total }\end{array}$ & 1 & $.888 \dagger$ & $.874 \dagger$ & $.860 \dagger$ \\
\hline Forgetfulness & & 1 & $.681 \dagger$ & $.771 \dagger$ \\
\hline Distractibility & & & 1 & $.608 \dagger$ \\
\hline $\begin{array}{c}\text { False } \\
\text { Triggering } \\
\end{array}$ & & & & 1 \\
\hline$T a b$ & $\begin{array}{l}\text { 3. Correlation betweer } \\
\text { and Three Subscale }\end{array}$ & $\begin{array}{l}\text { State } \\
\text { of Cog } 1\end{array}$ & $\begin{array}{l}\text { iety and Tot } \\
\text { e Failures }\end{array}$ & Score \\
\hline
\end{tabular}

Correlational analysis indicated a significant relationship between reported state anxiety and cognitive failures. As presented, all three subscales of cognitive failures, forgetfulness $(\mathrm{r}=.355, \mathrm{p}<0.01)$, distractibility $(\mathrm{r}=.427, \mathrm{p}<$ $0.01)$, false triggering $(\mathrm{r}=.347, \mathrm{p}<0.01)$ were statistically significant positive correlate with state anxiety. According to the results total score of cognitive failures have the highest correlation with anxiety $(r=.453, \mathrm{p}<0.01)$.
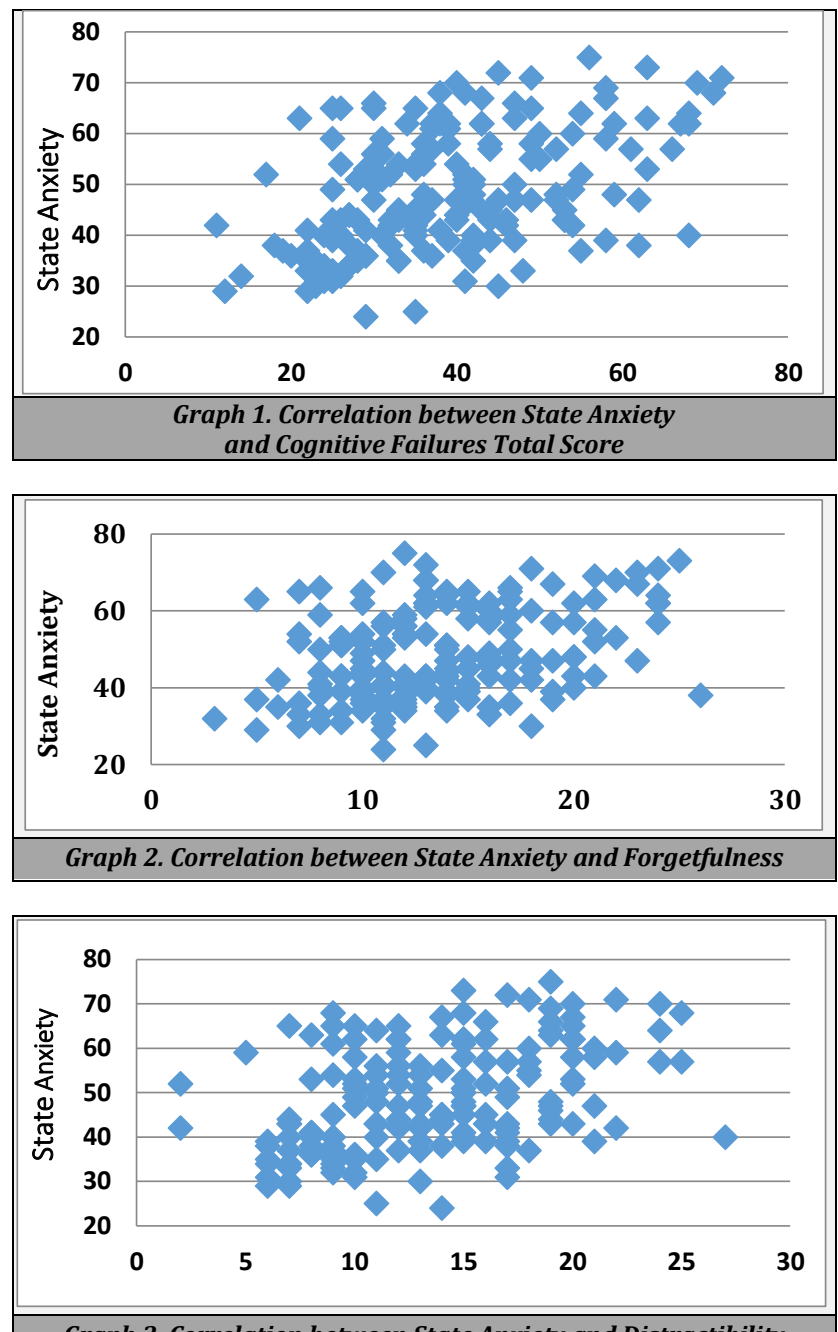

Graph 3. Correlation between State Anxiety and Distractibility

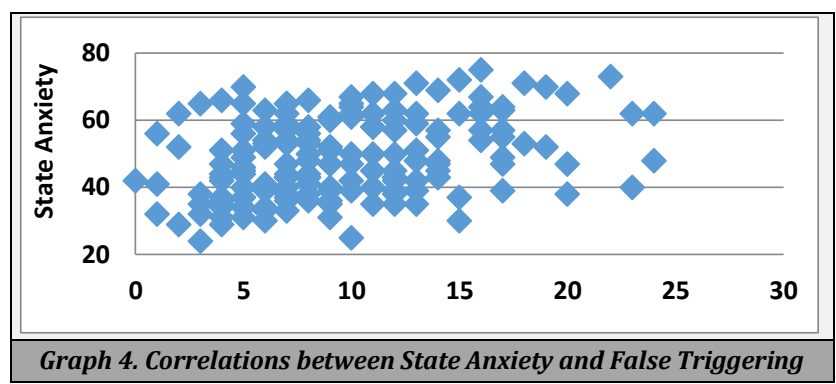

\section{DISCUSSION}

Variables analysed in this study such as consumption of pharmacotherapy, cigarettes, alcohol, and high level of anxiety could help to understand why cognitive failures in daily life of students happened. Anxiety was statistically significantly correlated with the total of cognitive failures, but also with 
the forgetfulness, distractibility and false triggering subscales. The largest association was with total CFQ score.

In our study, there were a statistically significant difference between students who consumed pharmacotherapy and students who did not consumed any pharmacotherapy in last month. Medicines such as antibiotics or medicine for chronic illnesses are medicines that students take with the recommendation of a physician, while for the medications such as analgesics we cannot be sure. According to the results obtained, we assume that in $68 \%$ of cases students used medicines independently without the supervision of a doctor. Medical students have used pharmacotherapy twice as much in comparison to psychology students. Indication for using painkillers was most commonly for headache, abdominal pain, menstrual pain, anxiety and stress. According to the data obtained, female students were more likely to use pharmacotherapy, $86.58 \%$ compared to $13.42 \%$ of men. This is in line with other studies ${ }^{16,17}$ where medical students had a high prevalence of self-medication (74.6\% - $75.2 \%$ of students). Taking into account the definition of International Association for the Study of Pain (IASP Task Force on Taxonomy, 1994), Moriarty ${ }^{18}$ states that pain is viewed as a perception, not a sensory modality that requires cognitive processing. In acute pain, people may have a problem in completing a task that may be interrupted or distracting; while in chronic pain, people experience difficulty with attention, memory and decision making. We assume that a large percentage of the use of analgesics to relieve various pains such a headache, abdominal pain can be caused by stressful situations and feelings of pressure. Also, students who are more likely to take painkillers suffer more pain before consuming the pill, and there is a presumption that they made cognitive failures as a result of these situations.

The individual differences found in self-reported cognitive failures appeared to depend on cigarette smoking and alcohol consuming. In our study smokers or alcohol consumers made statistically significantly more cognitive failures compared to students who did not consume nicotine or alcohol. According to the available literature, the results are inconsistent, and there is research suggesting that cigarette consumption affects cognitive and mental functions. Accordingly, in a study by Ahmad ${ }^{19}$, smokers had significantly lower cognitive functions and more cognitive failures than non-smokers. ${ }^{19,} 20$ It is significant to mention the research by Parrott \& Kaye ${ }^{21}$ that highlights the complexity of the relationship between cognitive failures and nicotine use. ${ }^{21}$ According to the research, smokers made more mistakes during the period of abstinence, attracted higher levels of stress, lower mood, decreased arousal, which they cite as the importance of nicotine for maintaining functioning in the persons using it. Nicotine can play an essential role in the regulation of emotions. ${ }^{6}$ According to a study by Russel, ${ }^{12}$ alcohol consumption has been linked to everyday stressors. In stressful environment students consumed more alcohol and on days when they were not under high stress consumed on average less alcohol. The role of stress exposure and student drinking suggests that drinking was stress related and a risk factor for future alcohol problems. According to Carrigan \& Barkus $^{6}$, there were a lack of papers examining the impact of alcohol on cognitive failures, despite a large body of work describing the impact of alcohol on executive functions, inhibitory controls, memory, and motor control. Drinking had an effect on executive functions and cognitive flexibility. The area of the brain that connects with mental flexibility is the dorsolateral prefrontal cortex. ${ }^{22}$ Studies show that there were differences in grey matter volume in dorsolateral prefrontal cortex in students who started consuming alcohol during adolescence. Differences are positively related to poorer performance in neurocognitive measures of executive functions. ${ }^{22}$

In this study, students who have high level of anxiety made statistically significant more cognitive failures than students whose level of anxiety were lower. Results in this study showed that anxiety was statistically significantly related with cognitive failures, but also with the forgetfulness, distractibility and false triggering subscales.

Relatively high levels of anxiety were associated with a tendency to forget something we had planned, or to have a harder time maintaining focus of attention in social situations or interrupting started cognitive or motor activity. Frequent cognitive failures were associated with anxiety, assuming that attention was split between not performing the cognitive task immediately and the person's internal psychological states that may be relevant to the concern. ${ }^{8}$ Irrelevant thoughts and negative emotions such as anxiety can inhibit the success of the task. ${ }^{2}$

According to a study by Varalakshmi et al ${ }^{23} 51.7 \%$ of firstyear students show high cognitive failures. There was also a high level of stress in students which were statistically significantly associated with cognition, and $61.6 \%$ of students reported moderate or very high anxiety. The results show that anxiety symptoms and stress were correlated with cognition.

In addition to the fact that cognitive failures research can contribute to a better understanding of the real-life play of cognitive processes, they also improve the ecological justification for human cognition research. ${ }^{6}$

Our study has several limitations. Firstly, we did not consider other psychological problems and other cognitive measures. Secondly, the study did not include students from other years on the basis of whom they could obtain more information about causally related relationships. Thirdly, the survey had only one measurement point, which deprives us of information about the stability of the examined variables.

For the future researcher it would be useful to know the history of consuming alcohol and pharmacotherapy, as how personality could predict cognitive failures.

\section{CONCLUSIONS}

Variables such as consuming alcohol, cigarettes, painkillers, and anxiety could affect cognitive failures. Student life in addition to the obligations and pressures created by academic engagement itself involves many changes such as adapting to a new environment, making new friends, higher financial costs that create stress, and just thinking about it can cause anxiety symptoms. Accordingly, the undesirable outcomes that cognitive failures can cause maladaptive student habits and anxiety should be a critical public health issue. Primary prevention can act to increase student selfesteem and better cope with stress through the organization of time, which later in the future could generalize to other stressful situations. 
Data sharing statement provided by the authors is available with the full text of this article at jemds.com.

Financial or other competing interests: None.

Disclosure forms provided by the authors are available with the full text of this article at jemds.com.

Conception and design, acquisition of data, or analysis and interpretation of data has been done by ADŽ, MKD and DL. Either drafting the article or revising it critically for important intellectual content has been done by ADŽ, MKD and DL. The final approval of the version to be published has been given by ADŽ, MKD and DL.

\section{REFERENCES}

[1] Broadbent DE, Cooper PF, FitzGerald P, et al. The cognitive failures questionnaire (CFQ) and its correlates. Br J Clin Psychol 1982;21(1):1-16.

[2] Wallace JC, Chen G. Development and validation of a work-specific measure of cognitive failure: implications for occupational safety. J Occup Organ Psychol 2005;78(4):615-32.

[3] Unsworth N, Brewer GA, Spillers GJ. Variation in cognitive failures: an individual differences investigation of everyday attention and memory failures. Journal of Memory and Language 2012;67(1):1-16.

[4] Unsworth N. Consistency of attentional control as an important cognitive trait: a latent variable analysis. Intelligence 2015;49:110-28.

[5] Kane MJ, Brown LH, McVay JC, et al. For whom the mind wanders, and when: an experience-sampling study of working memory and executive control in daily life. Psychol Sci 2007;18(7):614-21.

[6] Carrigan N, Barkus E. A systematic review of cognitive failures in daily life: healthy populations. Neurosci Biobehav Rev 2016;63:29-42.

[7] Boals A, Banks JB. Effects of traumatic stress and perceived stress on everyday cognitive functioning. Cogn Emot 2012;26(7):1335-43.

[8] Tirre WC. Dimensionality and determinants of selfreported cognitive failures. Int $\mathrm{J}$ Psychol Res 2018;11(1):9-18.

[9] Pluviano SA, Gamboz NA, Brandimonte MA. On the effect of stress on cognitive failures in everyday life: a look into prospective memory errors. Eur Acad Res 2015;3(9):9601-25.

[10] Farrer LM, Gulliver A, Bennett K, et al. Demographic and psychosocial predictors of major depression and generalised anxiety disorder in Australian university students. BMC Psychiatry 2016;16:241.
[11] Heydari R, Mobidi AM, Mohammadi R, et al. Effect of emotional distress and academic stress on level of nicotine addiction among medical students. Nova J Med Biol Sci 2017;6(1).

[12] Russell MA, Almeida DM, Maggs JL. Stressor-related drinking and future alcohol problems among university students. Psychol Addict Behav 2017;31(6):676-87.

[13] Carey KB, Scott-Sheldon LAJ, Carey MP, et al. Individuallevel interventions to reduce college student drinking: a meta-analytic review. Addict Behav 2007;32(11):246994.

[14] Spielberger CD. STAI state - trait anxiety Inventory for adults form: Review Set; manual, test, scoring key. Mind Garden 1983.

[15] Rast P, Zimprich D, Van Boxtel M, et al. Factor structure and measurement invariance of the cognitive failures questionnaire across the adult life span. Assessment 2009;16(2):145-58.

[16] Ibrahim NK, Alamoudi BM, Baamer WO, et al. Selfmedication with analgesics among medical students and interns in King Abdulaziz University, Jeddah, Saudi Arabia. Pak J Med Sci 2015;31(1):14-8.

[17] Brlić KČ, Holcer JN, Sović S, et al. Characteristics of selfmedication for pain relief among first-year health care students in Zagreb, Croatia. Psychiatr Danub 2014;26 Suppl 3:459-65.

[18] Moriarty O, McGuire BE, Finn DP. The effect of pain on cognitive function: a review of clinical and preclinical research. Prog Neurobiol 2011;93(3):385-404.

[19] Ahmadi E, Monsef FB. The survey of cognitive executive functions of brain in male smokers and non-smokers. J Rafsanjan U Med Sci 2015;14(9):803-10.

[20] Wan L, Friedman BH, Boutros NN, et al. Smoking status affects men and women differently on schizotypal traits and cognitive failures. Pers individ Differ 2008;44:42535.

[21] Parrott AC, Kaye FJ. Daily uplifts, hassles, stresses and cognitive failures: in cigarette smokers, abstaining smokers, and non-smokers. Behav Pharmacol 1999;10(67):639-46.

[22] Doallo S, Cadaveira F, Corral M, et al. Larger middorsolateral prefrontal gray matter volume in young binge drinkers revealed by voxel-based morphometry. PLoS One 2014;9(5):e96380.

[23] Varalakshmi VS, Karthick S, Jothy J. Prevalence of elevated blood pressure, stress, and anxiety and its association with cognitive failure among medical students - a crosssectional study. Natl J Physiol Pharmacy and Pharmacol 2020;10(3):232-5. 